\title{
A Novel Hybrid House Price Prediction Model
}

\author{
Sureyya Akyuz ${ }^{1}$, Birsen Eygi Erdogan², and Ozlem Yildiz ${ }^{3}$ \\ ${ }^{1}$ Bahcesehir Universitesi Muhendislik ve Doga Bilimleri Fakultesi \\ ${ }^{2}$ Marmara Universitesi \\ ${ }^{3}$ Bahcesehir University
}

October 16, 2020

\begin{abstract}
The real estate sector is evolving and changing rapidly with the increase in housing demand, and new luxury housing projects appear every day. The reliability of housing market investments is largely dependent on accurate pricing. The aim of this study is to introduce a dynamic pricing procedure that estimates housing prices using the most important attributes of a house. To this end, a hybrid modeling system is proposed employing linear regression, clustering analysis, nearest neighborhood classification, and the Support Vector Regression (SVR) method. The housing data of the Kadikoy area in Istanbul, collected via manual web scraping, was used for the raining and validation of the proposed algorithm. The results of the hybrid model were compared using multiple linear regression, ridge regression, and Support Vector Machines (SVMs). The experimental results show that the proposed model is superior, both in terms of Residual Mean Square Error (RMSE) and Mean Absolute Percentage Error (MAPE) measures. Therefore, the proposed dynamic hybrid modelling structure can be successfully used for predicting house pricing.
\end{abstract}

\section{Hosted file}

Sureyya_ozogur_akyuz.pdf available at https://authorea.com/users/362237/articles/487046-anovel-hybrid-house-price-prediction-model

\section{Hosted file}

Sureyya_ozogur_akyuz.tex available at https://authorea.com/users/362237/articles/487046-anovel-hybrid-house-price-prediction-model

\section{Hosted file}

Definitions.sty available at https://authorea.com/users/362237/articles/487046-a-novelhybrid-house-price-prediction-model

\section{Hosted file}

mybibfilehouses.bib available at https://authorea.com/users/362237/articles/487046-a-novelhybrid-house-price-prediction-model

\section{Hosted file}

elsarticle.dtx available at https://authorea.com/users/362237/articles/487046-a-novelhybrid-house-price-prediction-model 


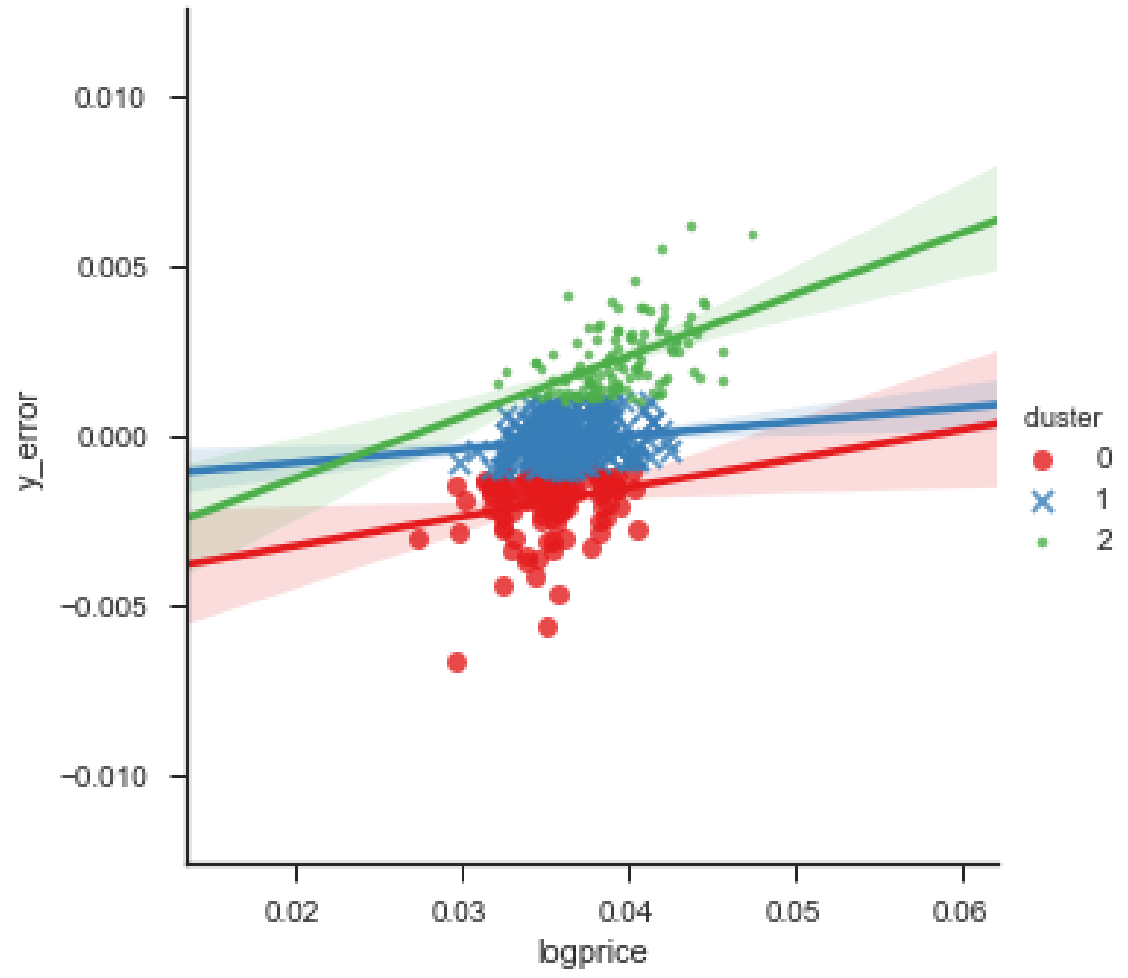




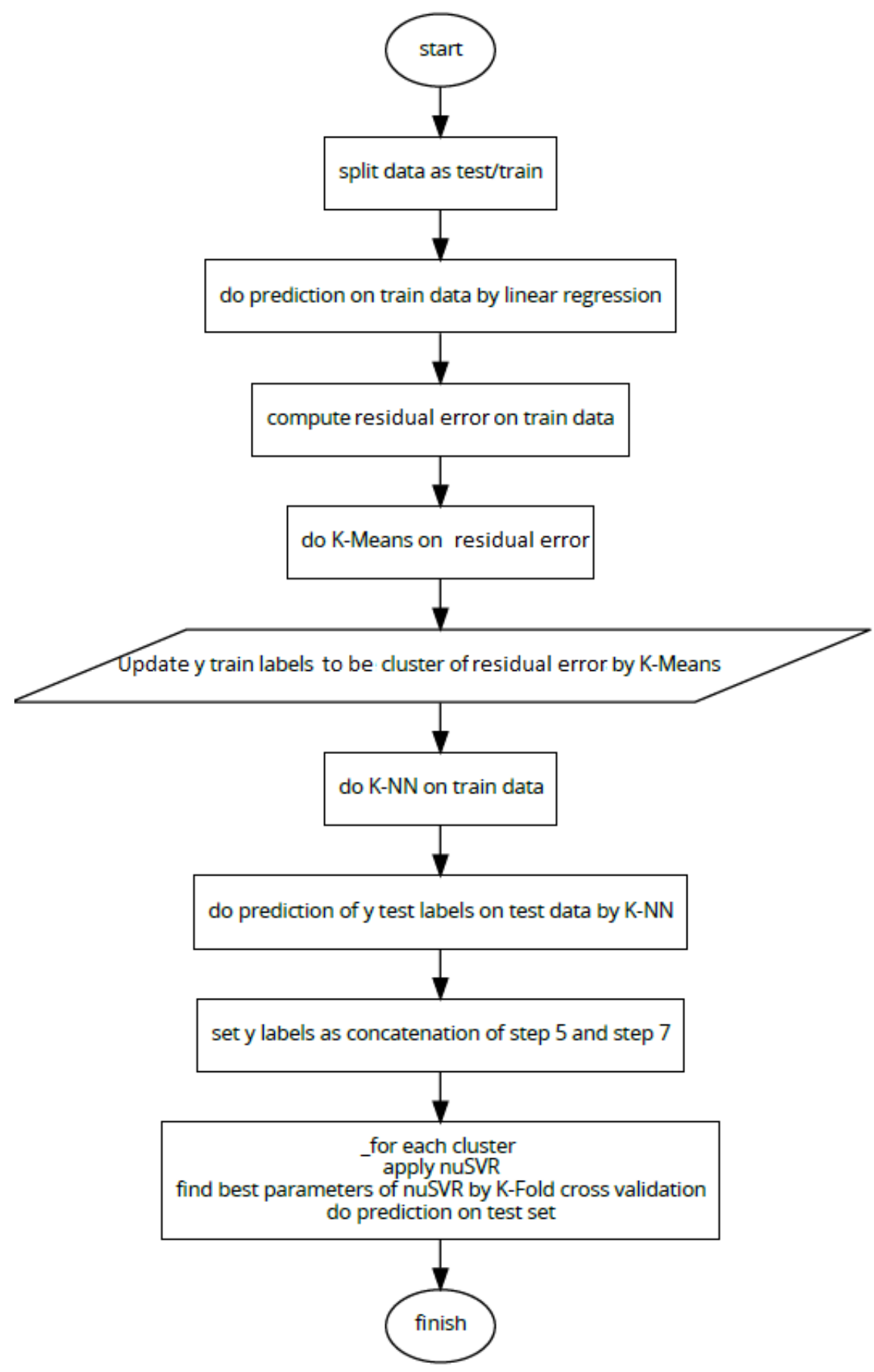




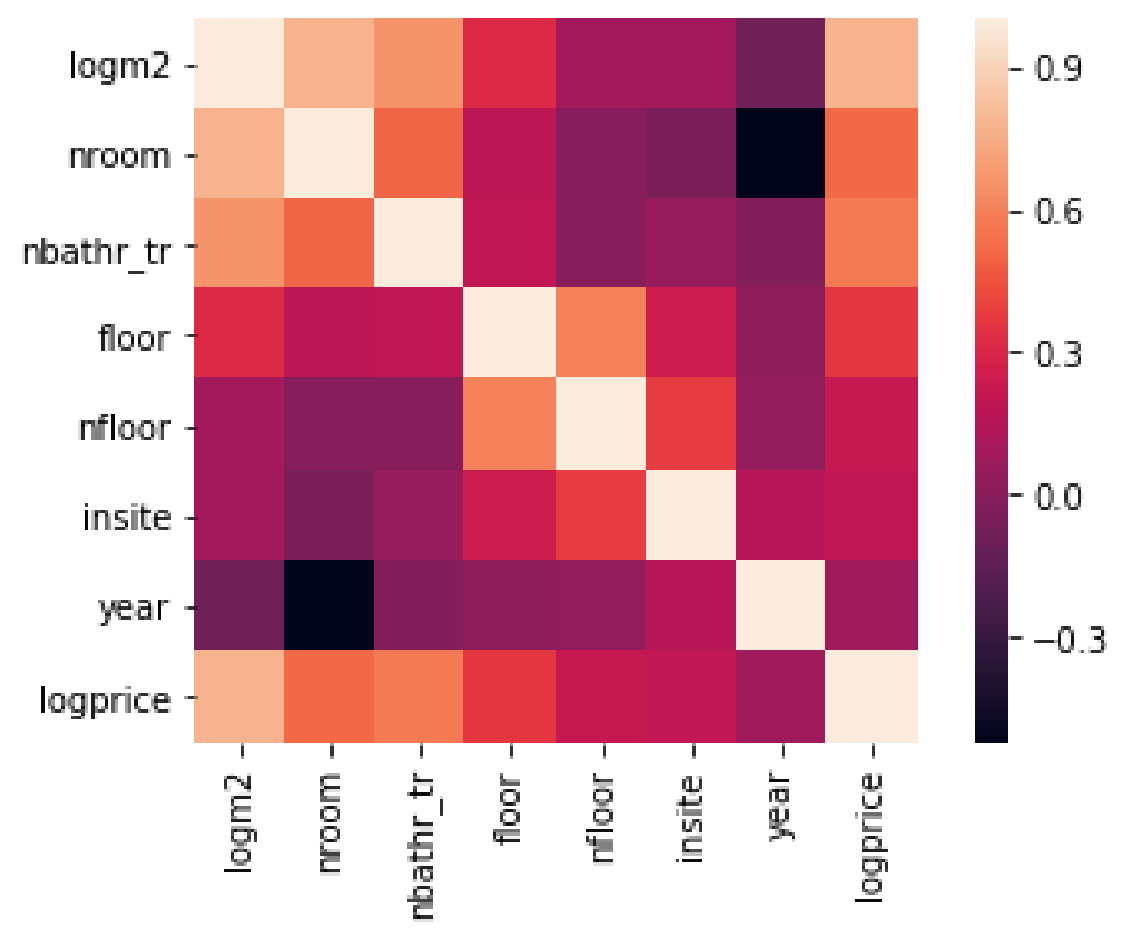

